\title{
Why do we have to move fluid to be able to breathe?
}

\author{
Martin Fronius*, Wolfgang G. Clauss and Mike Althaus \\ Molecular Cell Physiology, Institute of Animal Physiology, Justus-Liebig-University Giessen, Giessen, Germany
}

\section{Edited by:}

Francisco Javier Alvarez-Leefmans, Wright State University, USA

Reviewed by:

Francisco Javier Alvarez-Leefmans, Wright State University, USA

Francisco Fernandez De-Miguel,

Universidad Nacional Autonoma de

Mexico, Mexico

James D. Stockand, University of

Texas Health Science Center at San

Antonio, USA

\section{${ }^{*}$ Correspondence:}

Martin Fronius, Molecular Cell

Physiology, Institute of Animal

Physiology, Justus-Liebig-University

Giessen, Heinrich-Buff-Ring 26,

35392 Giessen, Germany.

e-mail:martin.fronius@

bio.uni-giessen.de
The ability to breathe air represents a fundamental step in vertebrate evolution that was accompanied by several anatomical and physiological adaptations. The morphology of the air-blood barrier is highly conserved within air-breathing vertebrates. It is formed by three different plies, which are represented by the alveolar epithelium, the basal lamina, and the endothelial layer. Besides these conserved morphological elements, another common feature of vertebrate lungs is that they contain a certain amount of fluid that covers the alveolar epithelium. The volume and composition of the alveolar fluid is regulated by transepithelial ion transport mechanisms expressed in alveolar epithelial cells. These transport mechanisms have been reviewed extensively. Therefore, the present review focuses on the properties and functional significance of the alveolar fluid. How does the fluid enter the alveoli? What is the fate of the fluid in the alveoli? What is the function of the alveolar fluid in the lungs? The review highlights the importance of the alveolar fluid, its volume and its composition. Maintenance of the fluid volume and composition within certain limits is critical to facilitate gas exchange. We propose that the alveolar fluid is an essential element of the air-blood barrier. Therefore, it is appropriate to refer to this barrier as being formed by four plies, namely (1) the thin fluid layer covering the apical membrane of the epithelial cells, (2) the epithelial cell layer, (3) the basal membrane, and (4) the endothelial cells.

Keywords: alveoli, alveolar fluid, alveolar fluid transport, breathing, gas exchange, air-blood barrier, three-ply, four-ply

\section{OXYGEN UPTAKE IN VERTEBRATES}

The transition from water to land constitutes a fundamental step in vertebrate evolution. This transition brought new challenges that required development of strategies to cover the oxygen demand needed for respiration in order to utilize the production of ATP. In all vertebrates specific surface structures were developed to facilitate the uptake of oxygen (Figure 1). The basic requirements of these structures are defined by (1) compartmentalization to increase the surface that is exposed to the breathing medium, (2) a barrier sufficiently thin to facilitate gas diffusion, and (3) increased vascularization of the gas-exchanging regions (Maina, 2002). The first two requirements reflect adaptations to basic physical principles imposed by diffusion of molecules. The relationship between these parameters that determine the rate of particle (gas) diffusion across a layer (body surface) follows the Fick's laws of diffusion (Fick, 1855).

In aquatic vertebrates the exchange of breathing gases is commonly facilitated by gills, which represent specialized evaginations of the body surface area (Maina, 2002), as illustrated in Figure 1. Lungs were developed during the water-land transition as an adaption to air-breathing. They represent invaginations of the body surface area (Figure 1). Invagination of the gas-exchanging body surface was a crucial step to avoid desiccation resulting from the extensive loss of water by evaporation. This is a problem faced by all organisms that live on land (including plants); only few organisms can tolerate desiccation to equilibrium with air (Alpert, 2006).

The main advantage of breathing air is the expanded access to oxygen, with constant levels of oxygen at different altitudes. Furthermore, compared to water, air is a more suitable breathing medium for various reasons: (1) the viscosity of air is much lower than that of water, facilitating ventilation; (2) the concentration of $\mathrm{O}_{2}$ is higher in air than in water; (3) the diffusion rates of $\mathrm{O}_{2}$ are greater in air than in water. These differences reflect basic physical principles between different states of aggregation (air/gas $\leftarrow \rightarrow$ water/fluid) but they also represent constrains for covering the oxygen demand under certain living conditions. For instance, it has been demonstrated that air-breathing vertebrates can survive by breathing oxygen-enriched liquids (Kylstra, 1974), although ventilating liquid consumes much more energy than ventilating air (Maina, 2000). In contrast, gills can take up oxygen, although they adhere, and collapse when they are exposed to air. Their architecture is not adapted to withstand the physical constraints imposed by air (Maina, 2002). This becomes evident when fish are exposed to air; they die from asphyxiation in spite of the fact that the oxygen content of air is much higher than that of water. The cause of death is desiccation of the gills that leads to adherence of the gill filaments, which ultimately results in a gradual decrease of the gas-exchanging surface area.

Regardless of the anatomical differences, gills and lungs represent specialized parts of the body surface area with particular features that represent adaptations to living conditions. In the sections that follow we discuss these requirements and adaptations for the function of the lung as a gas-exchange organ.

\section{EPITHELIAL CELLS FORM THE BODY SURFACE AREA OF THE LUNGS}

The surface of the lung is formed by a continuous layer of epithelial cells, which are sealed together at their apical side (air-facing) by 


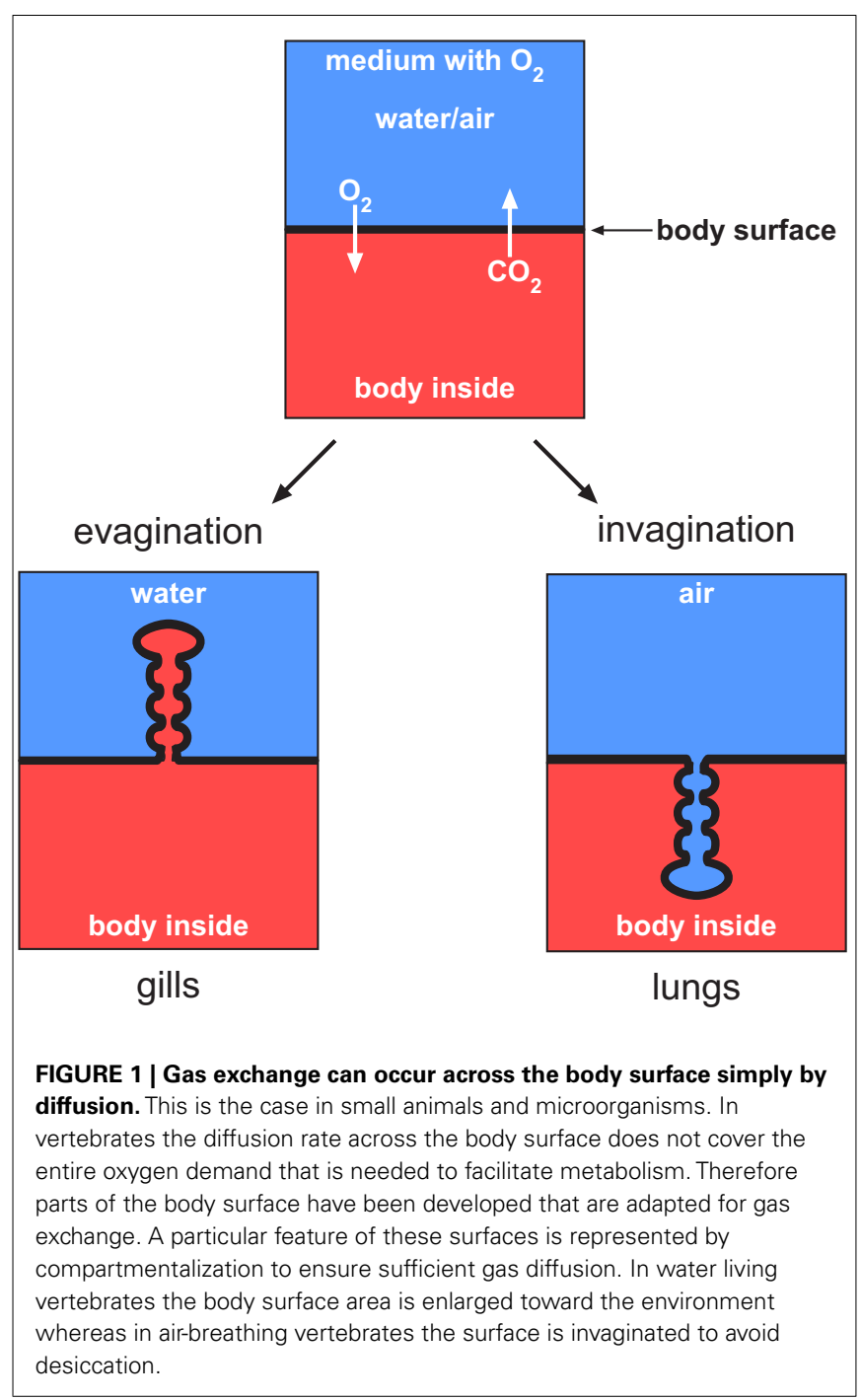

tight junctions. Correlating with their location and specific function, pulmonary epithelial cells exhibit different anatomical and morphological properties. In general, one can differentiate airway epithelial cells and alveolar epithelial cells. Airway epithelial cells, for example, have columnar/cuboidal shape and the bulk of them are ciliated (Jeffery and Reid, 1975; Pack et al., 1981). By contrast, alveolar epithelial cells lack cilia and their shape is optimized to facilitate gas exchange. Accordingly, these cells are very thin $(0.1-0.2 \mu \mathrm{m})$ and elongated (Matthay et al., 2002). In mammalian lungs, two different types of alveolar epithelial cells have been identified and named type I, and type II. Type I cells cover almost $95 \%$ of the alveolar surface area, although they constitute only $1 / 3$ of the total number of alveolar epithelial cells (Stone et al., 1992). By contrast, type II cells are relatively small and cuboidal. They are more numerous than type I cells, although they cover only the remaining $5 \%$ of the alveolar surface area (Stone et al., 1992). From an evolutionary perspective the prototype of alveolar cells within air-breathing vertebrates is represented by cells that are similar to type I alveolar epithelial cells. For instance, in amphibian lungs only cells having a shape similar to that of alveolar epithelial type I cells are found (Okada et al., 1962; Dierichs, 1973; Meban, 1973; Fischer et al., 1989). Type II cells, as found in mammalian lungs, can be considered an adaption to the miniaturization of the alveoli. These cells produce surfactant, which avoids collapsing of the alveoli - a problem which is a consequence of miniaturization (Daniels et al., 1994; Goerke, 1998). Therefore, it can be hypothesized that the primary alveolar epithelial cells developed during the transition from water to land were type Ilike epithelial cells. The differentiation of alveolar epithelial cells (type I and type II), as observed in mammalian lungs, is likely a consequence of alveolar miniaturization that occurred later in evolution.

Interestingly, the basic architecture of the gas-exchanging region in the distal parts of the lung is highly conserved within airbreathing vertebrates (Amphibia, Reptilia, Aves, and Mammalia). The architecture of this region has been referred to as the "three-ply design" (Maina and West, 2005). This three-ply model consists of three basic elements: (1) epithelial layer, (2) the basal membrane, and (3), the endothelial cells (Figure 2).

Besides these three elements, the apical side of the epithelial cells is entirely covered by a thin fluid layer (Figure 2). In the airways this fluid layer is usually referred to as "airway surface layer," whereas in the distal lung region it is called "alveolar lining fluid" (ALF). The present review focuses on the ALF in the distal (gas-exchanging) regions of the lungs. We discuss the functional significance of this fluid layer for proper lung function and propose that it should be considered as a fourth ply of the air-blood barrier of air-breathing vertebrates.

\section{WATER IN THE DISTAL LUNG}

An example illustrating the fact that our lungs are "fluid-filled" is the everyday life observation that breathing against a cold window will immediately result in misted windows. The phenomenon is due to condensation of exhaled water originating from the lungs.

How much fluid our lungs have? The fluid content in the lungs is distributed in three different compartments: (1) capillaries, (2) interstitial space, and (3) alveolar airspace (Figure 3). The capillaries contain $\sim 65 \mathrm{ml}$ fluid (Levis et al., 1959) and the extravascular fluid is estimated to be $<500 \mathrm{ml}$ (Lindert et al., 2007). The bulk extravascular fluid fills the interstitial spaces, whereas only a small fraction is localized in the alveoli. The fluid within the alveoli, often referred to as alveolar fluid, is part of the alveolar surface network (Scarpelli, 2003). This network within the alveoli can be envisaged as a foam made of surfactant and water. The foam forms a network within the alveoli and has a gas:fluid volume ratio of 900:1 (Scarpelli, 2003). Part of the fluid of the alveolar surface network covers the entire apical surface of the alveolar epithelial cells (Bastacky et al., 1995) as illustrated in Figure 2, whereas another portion of the fluid flows through nanometer-thin tunnels formed by the surfactant (Scarpelli, 2003), as illustrated in Figure 3.

The intermediate surface area of the human lung is $\sim 130 \mathrm{~m}^{2}$ (Weibel, 2009) and is mostly constituted by the alveolar region. The average fluid surface height in the alveoli is $\sim 0.2 \mu \mathrm{m}$ (Bastacky et al., 1995). From these values (surface area and fluid height) the alveolar fluid content can be estimated to be $\sim 36 \mathrm{ml}$. It has been suggested that most of this fluid covers the apical alveolar surface of the epithelial cells (Figure 3). This might be an underestimation 

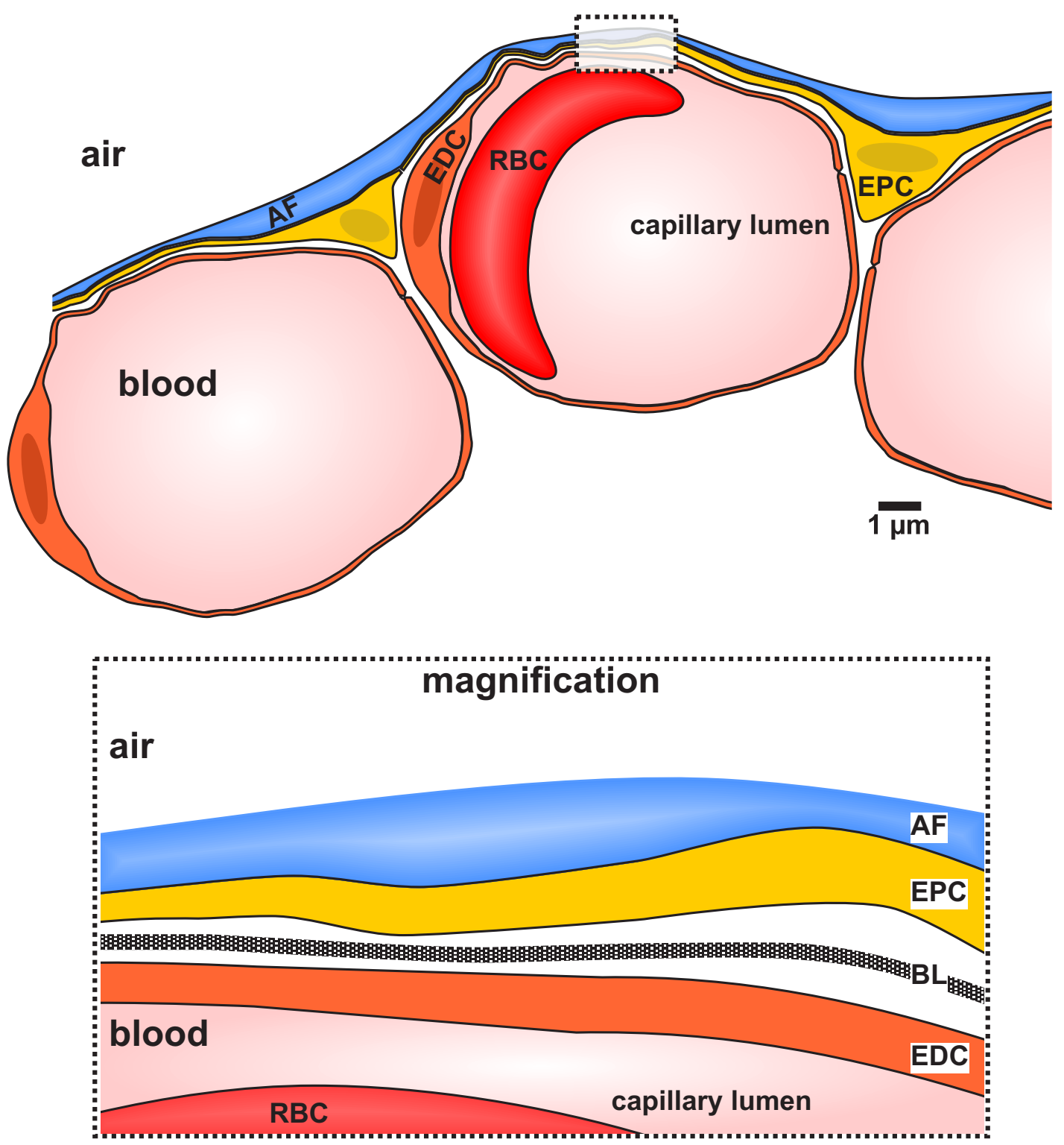

FIGURE 2 | Diagram illustrating a cross section of the distal part of a vertebrate lung displaying the elements forming the air-blood barrier. The diagram is based on an original electron micrograph of a cross section of a lung of Xenopus laevis (Fischer et al., 1989). The Air-blood barrier is formed by the epithelium, the basal lamina, and the endothelium. The apical side of the epithelium is covered with a fluid layer (alveolar fluid, blue color). AF, alveolar fluid; EDC, endothelial cell; EPC, epithelial cells; RBC, red blood cell. The box represents a magnification of the air-blood barrier depicting the distinct layers. The basal lamina $(\mathrm{BL})$ is clearly visible. since there is additional fluid flowing through the tunnels of the alveolar surface network (Scarpelli, 2003), which is not considered.

It is estimated that approximately one fourth of the daily water requirements of a human being are used up by water loss during respiration (Kleiner, 1999). Thus, assuming that a 70-kg human needs $\sim 2900 \mathrm{ml}$ of water per day (Kleiner, 1999) $\sim 725 \mathrm{ml} /$ day of this water will be lost due to respiration. This water fraction originates primarily from fluid in the alveoli and yet the alveolar fluid volume is kept constant. This indicates that the alveolar fluid volume is replaced $\sim 20$ times/day. Clearly, water loss due to respiration and its replacement from the internal water body content is a dynamic process that must be tightly regulated.

Where does this water come from? What is its functional significance?

\section{EVOLUTIONARY ORIGIN}

The ALF might be regarded as an evolutionary vestige from the origin of life in water (Weibel et al., 1993; Bastacky et al., 1995; Daniels and Orgeig, 2003). In fact, from fish to mammals, the lungs of air-breathing vertebrates contain water, part of which forms a 

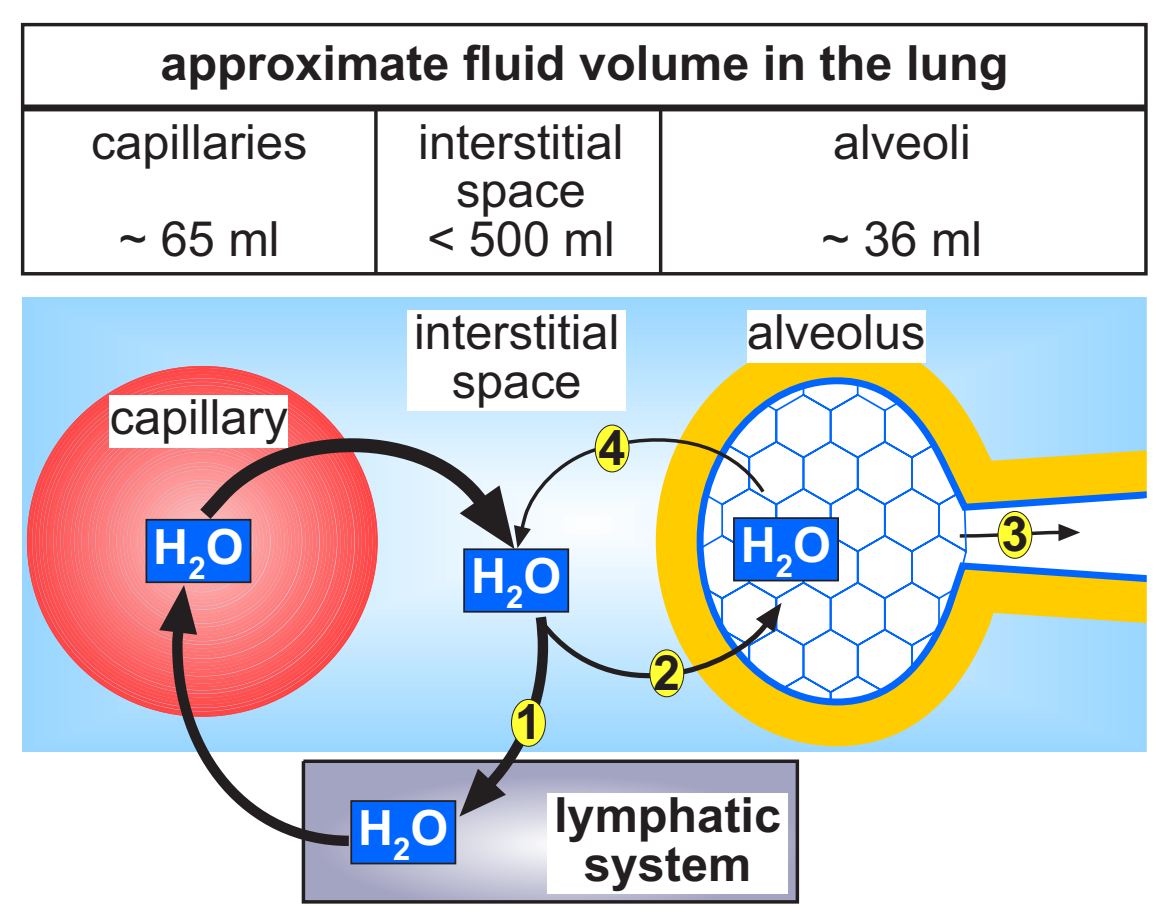

FIGURE 3 | Circular flow of water in the lung. The water within the alveoli originates from the pulmonary capillaries. The bulk of fluid in the mammalian lung is supposed to be localized in the interstitial space of the lung. From here the greatest part is drained (1) via the pulmonary lymphatic system and thus returned to the vascular system. A small portion of the fluid within the interstitial space enters the alveoli (2). From the fluid inside the alveoli one part evaporates and is exhaled during respiration (3). In order to balance the fluid content in the alveoli, another part of the alveolar fluid is reabsorbed (4) by the activity of the alveolar epithelial cells back to the interstitial space from where it can be drained (1) back to the vascular system. thin layer covering the entire epithelia in the gas-exchange regions of the lungs (Daniels and Orgeig, 2003). A possible explanation of why this fluid is "conserved" during vertebrate evolution is the well-known fact that living eukaryote cells (including pulmonary epithelial cells) can only survive in an aqueous milieu. Water is necessary for electrolyte equilibrium, the assembly of proteins as well as the integrity of the lipid bilayer that forms the cell membrane (Billi and Potts, 2002). If pulmonary epithelial cells were directly exposed to air, they would die from desiccation within minutes. At this point we must consider that body surfaces directly exposed to air (e.g., the human skin) are usually formed by a multi-layered epithelium, which outermost layer consists of dead cells.

\section{PHYSIOLOGICAL ORIGIN}

As mentioned earlier, a significant amount of water is exhaled during respiration and needs to be replaced from the body interior. Two different mechanisms have been proposed to explain water movement into the alveoli: (1) A pressure gradient between the capillaries/interstitium and the alveolar airspace (which equals more or less the atmospheric pressure). This gradient leads to filtration of fluid into the alveoli. According to Starling's basic concept, the movement of water across a capillary is determined by pressure and osmotic gradients between the capillaries and the interstitium (Aukland, 1984). The same principle(s) might account for the flux of water from the interstitium to the alveolar airspace. Water transport in this context has been suggested to occur via paracellular pathways, the rate-limiting step being the resistance of the tight junctions. The concept of osmotically driven or hydrostatic pressure-driven water flux into the airspace is supported by the fact that alveolar water accumulation can be observed as a consequence of an increased pressure gradient and/or a leaky epithelial barrier - a pathological situation known as pulmonary edema. This is evident in patients having increased pulmonary blood pressure, e.g., due to heart failure (Murray, 2011) or hypoxic pulmonary vasoconstriction at high altitudes and/or low oxygen levels (Maggiorini, 2006), or tissue damage with disruption of the alveolar-capillary barrier (Murray, 2011) - both being factors leading to the development of edema.

(2) Water is secreted by the alveolar epithelial cells. There is evidence that $\mathrm{Cl}^{-}$secretion by alveolar epithelial cells is accompanied by water flow from the interstitium to the airspace (Lindert et al., 2007). However, the mechanisms by which water is transported across alveolar epithelial cells leading to the formation of alveolar fluid are not understood. There is evidence that water can be transported even against osmotic gradients (Zeuthen, 2010) by coupling its movements to the transport of a substrate that energizes its uphill transport. Likely molecules for such a mechanism are the $\mathrm{Na}^{+} / \mathrm{K}^{+} / 2 \mathrm{Cl}^{-}$cotransporter NKCC1 (Hamann et al., 2010) and some $\mathrm{K}^{+} / \mathrm{Cl}^{-}$cotransporters (Zeuthen, 2010). The activity of the basolaterally localized NKCC1 of alveolar epithelial cells could mediate the uptake of water into the epithelial cells, a hypothesis that needs to be tested. The exit pathway in the apical membrane, at least in type I cells, could be AQP5 known to be expressed in the apical membrane of these cells (Verkman, 2007). Other possible candidates are the $\mathrm{K}^{+} / \mathrm{Cl}^{-}$cotransporters but so far there 
is no evidence for their expression in these cells. At present, the mechanisms by which water is transported into the alveolar airspace remains to be elucidated. None of the possible mechanisms considered above are mutually exclusive. Mechanisms of water transport across alveolar epithelial cells are further discussed below in Section "Transepithelial Routes for Water Transport From the Airspace to the Interstitium.”

\section{WHAT IS THE FATE OF THE WATER IN OUR ALVEOLI?}

As already mentioned, part of the water from the surface of the lungs evaporates and leaves the body during exhalation. The amount of water exhaled is estimated to be $\sim 700 \mathrm{ml} /$ day. To maintain the amount of water covering the alveolar surface constant, the water loss by exhalation must be replaced with water from the capillaries and/or interstitium. Independently of the mechanisms by which water is transported to the alveolar surface (see Physiological Origin), two questions arise: (1) how alveolar water content is sensed? and (2) which are the mechanisms that keep the alveolar water at constant levels? i.e., how alveolar water content is regulated and maintained at a constant level?

The first question has a simple answer: we do not know! The only thing that is clear is that alveolar water originates from the interstitial space and from the pulmonary blood capillaries (Figure 3). As for the second question: fluid reabsorption from the alveolar airspace, i.e., the apical side of the alveolar epithelium, is a possible mechanism involved in regulating the content of water in the alveoli. There is a convincing body of evidence demonstrating that $\mathrm{Na}^{+}$absorption is a major function of alveolar epithelial cells (Hollenhorst et al., 2011). The vectorial transport of $\mathrm{Na}^{+}$ across the alveolar epithelium generates an osmotic gradient which causes the reabsorption of water from the apical side to the interstitium (Dobbs and Johnson, 2007). Control of $\mathrm{Na}^{+}$reabsorption by regulating the activity of the involved proteins $\left(\mathrm{Na}^{+}\right.$channels and the $\mathrm{Na}^{+} / \mathrm{K}^{+}$-ATPase) allows regulation of both the osmotic gradient and the rate of water transport across the epithelium. Most of the reabsorbed fluid in the interstitial space is drained by the pulmonary lymphatic system (Staub, 1970; Aukland and Reed, 1993; Murray, 2011). Thus, ion transport by alveolar epithelial cells, $\mathrm{Na}^{+}$reabsorption in particular, represents a major mechanism in alveolar fluid balance. In sum, alveolar water either evaporates through exhalation, or it is reabsorbed by the alveolar epithelium and eventually drained through the pulmonary lymphatic system (Figure 3).

\section{FUNCTION, MALFUNCTION, REGULATION, AND TRANSPORT ROUTES OF THE ALVEOLAR FLUID}

From the previous sections of this review we conclude that the fluid volume in the alveoli must be tightly regulated. Now we focus on the functions of the alveolar fluid and its importance for pulmonary physiology. We further discuss the basic mechanisms underlying alveolar fluid regulation and water reabsorption across the alveolar epithelium.

\section{FUNCTIONS OF THE ALVEOLAR FLUID}

(1) The alveolar fluid functions as a protection layer. The fluid represents the outermost layer of the alveolar surface that is directly exposed to air and thus to the environment. Alveolar fluid prevents desiccation of the epithelial cells and also functions as a physical protection barrier against inhaled particles and irritants. These functions of the alveolar fluid cannot be overemphasized considering that we breathe more than 7000 liters of air per day-including pollution particles and a variety of pathogens (Martin, 2000).

(2) Alveolar fluid also works as a solvent for various factors and compounds that are crucial for lung function such as the molecules that constitute the surfactant, antimicrobial peptides, or cytokines (Figure 4). The pulmonary surfactant in particular has been considered as "...the key to the evolution of air-breathing. ..” (Daniels and Orgeig, 2003). The surfactant reduces the alveolar surface tension at the air-liquid interface. Such surface-active agents have been identified in the lungs of all air-breathing vertebrates (Orgeig et al., 2007) including air-breathing fish (Daniels et al., 2004). The development of a surfactant system is thus crucial for air-breathing. As pointed out in Section "Epithelial Cells Form the Body Surface Area of the Lungs" of the present review, the compartmentalization and miniaturization of lungs during vertebrate evolution would have not been possible without those molecules. Conversely, the alignment of the amphiphilic surfactant molecules, which is necessary to fulfill their function as part of the alveolar surface network and to minimize lung compliance, would not be possible without water in the alveoli.

(3) Alveolar fluid also plays a critical role in the immune system intrinsic to the lungs; it constitutes the environment of alveolar macrophages (AMs), as illustrated in Figure 4. AMs are part of the innate immune system in the distal lung (Lambrecht, 2006) where they are covered by the alveolar fluid (Bachofen and Schurch, 2001). They phagocytose inhaled particles that are trapped by the alveolar fluid thereby keeping it sterile (Ng et al., 2004). To be able to carry their function, AMs need to move and this is only possible in a liquid environment. Besides AMs, there are various substances in the alveolar fluid that are part of the innate pulmonary immune system. These include the immune-reactive surfactant proteins $A$ and $D, \beta$ defensin, as well as pro- anti-inflammatory cytokines that are produced and released either by AMs or by the epithelial cells (Ng et al., 2004), as illustrated in Figure 4. The function of these antimicrobial proteins is also determined by the composition of the alveolar fluid. For instance, a change in $\mathrm{pH}$ of the alveolar fluid is sufficient to influence the innate immune response ( $\mathrm{Ng}$ et al., 2004). Further, the activity of defensins depends on the ionic composition of the alveolar fluid (Ganz, 2003).

(4) Alveolar fluid mediates gas transfer (Figure 4); as a fluid layer at the apical side of the alveolar epithelial cells it contributes to the diffusion distance for breathing gases. Increasing the amount of water of the ALF, for example, will increase its height (volume). This also increases the diffusion distances for $\mathrm{O}_{2} / \mathrm{CO}_{2}$, which affects - in accordance to Fick's law of diffusion - the rates of diffusion of these gases (Weibel et al., 1993; Sznajder, 2001; Hoschele and Mairbaurl, 2003). In addition, the diffusion rate of gases can be influenced by the chemical composition of the alveolar fluid and the surfactant (Ladanyi et al., 1992; Connor et al., 2001). Furthermore, there 


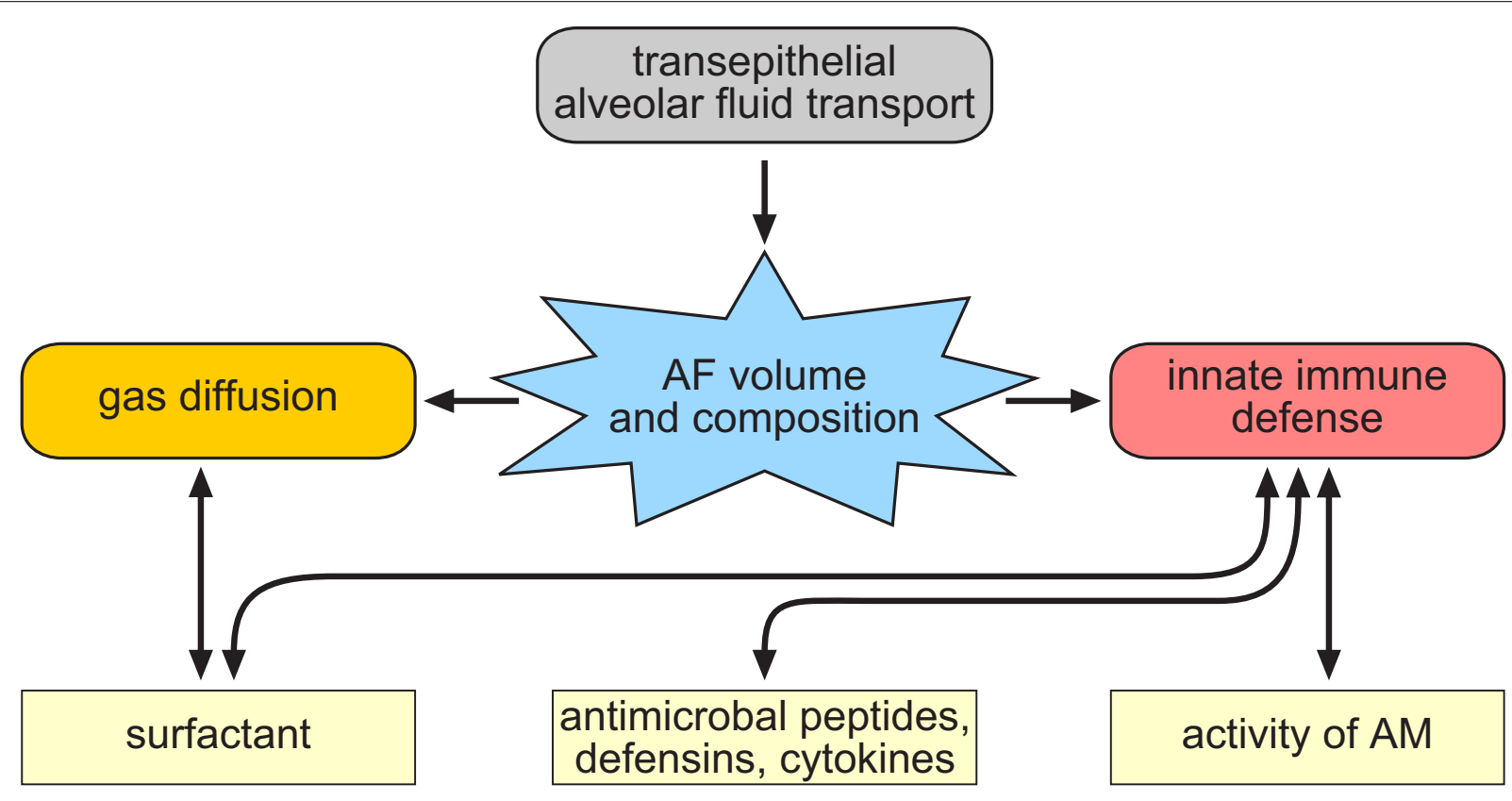

FIGURE 4 | Scheme that illustrates the interrelationship of alveolar fluid transport and the physiological functions related to the composition and volume of the alveolar fluid (AF). The volume and composition of the $A F$ is regulated by transepithelial ion transport processes. The fluid volume and the composition of the AF is a critical factor that influences gas exchange as well as innate immunity responses in the lung. This is due to the fact that the volume of the AF influences gas exchange since the fluid is part of the diffusion distance for the breathing gases. In addition, there is evidence that the surfactant molecules within the AF affect the diffusion of gasses. Further, the composition of the AF influence the activity of different factors that dissolved in the AF and these factors are part of the innate immune system in the lung (e.g., surfactant, antimicrobial peptides, defensins, cytokines as well as the immune cells such as alveolar macrophages). is evidence that the rate of water evaporation is also influenced by the composition of the alveolar fluid (Rantamaki et al., 2011).

\section{MALFUNCTIONS OF THE ALVEOLAR FLUID}

The functions of alveolar fluid are disturbed by changes in its water volume. There are several pathologic conditions associated with malfunction of alveolar fluid. For example, the accumulation of alveolar fluid occurring under pulmonary edema (independent of its cause) leads to inefficient blood oxygenation and thus to hypoxia (Althaus et al., 2011). Interestingly, the formation and/or resolution of pulmonary edema are tightly linked to transepithelial ion transport processes of alveolar epithelial cells. For example, there is evidence that hypoxia (e.g., as observed in high altitudes, or as a consequence of edema formation) correlates with a decreased expression of ion transport proteins in alveolar epithelial cells (Planes et al., 1996, 2002; Mairbaurl et al., 1997; Wodopia et al., 2000). Independent of the cause of "water flooding" epithelial ion channels and transporters are major targets of new therapeutic interventions in patients with pulmonary edema (Davis and Matalon, 2007).

By contrast to conditions leading to pulmonary edema, the hyperabsorption of ions, and fluid by the alveolar epithelial cells is also critical. Although there are no studies demonstrating that decreased volume of the alveolar fluid is associated with pathological conditions, this is evident in the airway disease cystic fibrosis. In these patients a mutated $\mathrm{Cl}^{-}$channel, Cystic Fibrosis transmembrane conductance regulator (CFTR; Riordan et al., 1989) causes thickening of the airway surface layer due to dehydration (Clunes and Boucher, 2007). This results in impaired mucociliary clearance. Although the mechanisms underlying alterations in ion transport function at the onset and progression of cystic fibrosis lung disease are still under debate, it is evident that mucus dehydration due to impaired ion transport mechanisms is a prerequisite for the onset of the disease (Clunes and Boucher, 2007; Stoltz et al., 2010).

Although the above example describes the situation in the airways and not in the alveoli, it is reasonable to assume that disturbances in ion transport mechanisms in patients with cystic fibrosis also affect lung functions in the alveolar region. Consistent with this idea, increased inflammation of the distal lung regions has been observed in transgenic animals that develop cystic fibrosis lung disease (Mall et al., 2004; Stoltz et al., 2010; Kimura et al., 2011). Two possibilities might explain the increased inflammation in the distal lungs of these transgenic animals: (1) decreased mucociliary clearance in the airways resulting in accumulation of pathogens in the distal lung; or (2) alterations in volume and composition of the alveolar fluid that influence the activity of AMs (Ganz, 2003; Ng et al., 2004). Given that ALF is critical for innate immune defense (see Functions of the Alveolar Fluid), it is reasonable to hypothesize that the innate immune response within the alveoli is also affected by changes in the alveolar fluid composition in patients with cystic fibrosis lung disease. 


\section{REGULATION OF ALVEOLAR FLUID COMPOSITION: ION TRANSPORT MECHANISMS REGULATE THE WATER CONTENT IN THE ALVEOLI}

Based on the evolutionary origin of alveolar fluid as well as its physiological and pathophysiological importance for lung function, it seems obvious to assume that the evolution of vertebrate lungs was accompanied by the development of epithelial ion transport mechanisms. These mechanisms are crucial in controlling the volume and composition of the alveolar fluid. Active ion transport processes in alveolar epithelial cells generate transepithelial osmotic gradients that provide the driving force for passive diffusion of water (Matthay et al., 2002; Hollenhorst et al., 2011), as illustrated in Figure 5. Alveolar epithelial cells are characterized by their ability to reabsorb $\mathrm{Na}^{+}$from the alveolar fluid by a two-step process: an electrochemical gradient ensures $\mathrm{Na}^{+}$ influx via $\mathrm{Na}^{+}$permeable channels such as Epithelial $\mathrm{Na}^{+}$Channel $(\mathrm{ENaC})$. These channels are localized in the apical membrane of the epithelial cells. Subsequently, $\mathrm{Na}^{+}$is extruded across the basolateral membrane via the $\mathrm{Na}^{+} / \mathrm{K}^{+}$-ATPase (Figure 5), a mechanism identified by Koefoed-Johnsen and Ussing (1958) in frog skin preparations. This regulatory principle for balancing ion homeostasis is highly conserved in evolution; it has been identified in annelids (Weber et al., 1993; Krumm et al., 2005) and facilitates electrolyte and water transport and balance in multiple vertebrate organs, such as kidneys or the colon (Garty and Palmer, 1997).

Although the mechanisms of $\mathrm{Na}^{+}$reabsorption by the concerted activity of ENaC and the $\mathrm{Na}^{+} / \mathrm{K}^{+}$ATPase are well described in alveolar epithelial cells, relatively little is known about the distinct contribution of $\mathrm{Cl}^{-}$and $\mathrm{K}^{+}$channels. For example, data concerning the role of CFTR in the distal lung epithelium are conflicting. Some authors suggest that CFTR participates in $\mathrm{Cl}^{-}$ uptake and thus $\mathrm{Cl}^{-}$reabsorption (Fang et al., 2006), whereas others have demonstrated that CFTR is involved in $\mathrm{Cl}^{-}$secretion (Lindert et al., 2007; Sommer et al., 2007). These discrepancies might be due to the use of different models and techniques. Nevertheless, these examples show the need of further studies to clarify the contribution of CFTR and $\mathrm{Cl}^{-}$transport in the regulation of alveolar fluid.

A long-neglected but likely decisive factor for balancing $\mathrm{Na}^{+}$ reabsorption (Wilson et al., 2006; Greenwood et al., 2009) and $\mathrm{Cl}^{-}$ secretion (Mall et al., 2000, 2003) are $\mathrm{K}^{+}$channels. $\mathrm{K}^{+}$channels regulate the membrane potential of the epithelial cells and consequently the driving force for electrodifussional $\mathrm{Na}^{+}$influx and $\mathrm{Cl}^{-}$efflux. Until now, a tremendous heterogeneity of $\mathrm{K}^{+}$channels (transcripts of $\sim 40$ different types of $\mathrm{K}^{+}$channels) has been identified in the lung (Bardou et al., 2009). Paradoxically, our knowledge about the physiological role of $\mathrm{K}^{+}$channels in pulmonary epithelial cells is limited to their role in the maintenance and control of the membrane potential. The question arises as to why pulmonary epithelial cells need so many different types of $\mathrm{K}^{+}$ channels.

The above examples on the role of CFTR and $\mathrm{K}^{+}$channels in alveolar epithelial cells make evident that the machinery of transepithelial ion transport processes in the alveoli is poorly understood. Furthermore, our picture about these processes is based primarily on functional electrophysiological studies performed under quiescent conditions. However, the lung is a highly dynamic organ whose cells are permanently exposed to different physical forces (e.g., strain and shear stress). There is preliminary evidence that physical forces that appear under normal breathing conditions can also influence ion transport processes in the alveolar region (Bogdan et al., 2008) and in the airways (Tarran et al., 2006).

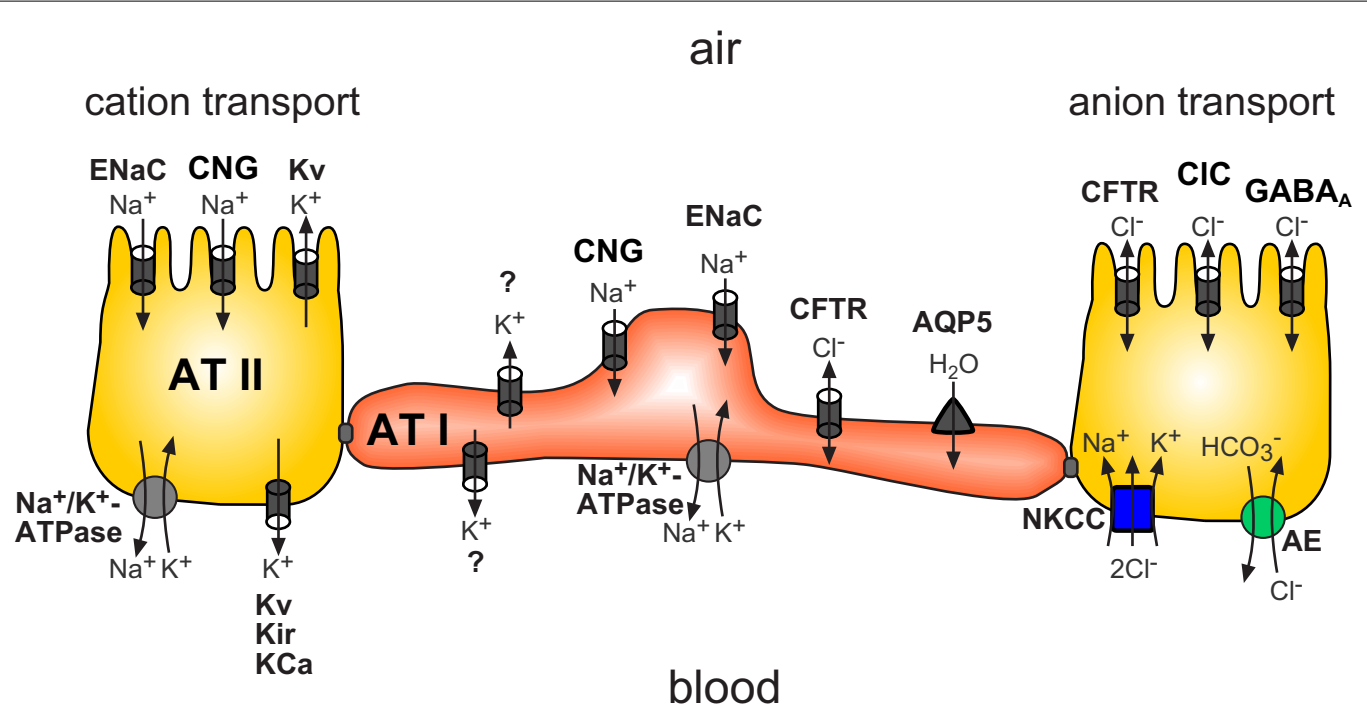

FIGURE 5 | Scheme illustrating the main ion transport proteins of alveolar epithelial cells (alveolar type I: AT I in red and alveolar type II: AT II in yellow) participating in transepithelial ion transport. Findings depicted in this figure are primarily derived from studies investigating the expression/presence of the molecules. ENaC, epithelial $\mathrm{Na}^{+}$channel; CNG, cyclic-nucleotide-gated channel; Kv, voltage-gated potassium channels; $\mathrm{Na}^{+} / \mathrm{K}^{+}$-ATPase, sodium/potassium ATPase; Kir, inward rectifying $\mathrm{K}^{+}$channel;
$\mathrm{KCa}$, calcium-activated potassium channel: CFTR, cystic fibrosis transmembrane conductance regulator; $\mathrm{ClC}$, voltage-sensitive $\mathrm{Cl}^{-}$channels; GABAA, $\gamma$-aminobutyric acid type $\mathrm{A} \mathrm{Cl}^{-}$channel; NKCC, sodium/potassium two chloride cotransporter; $A E$, anion exchanger). AT I cells are similarly equipped with ion transporting proteins. In addition these cells express aquaporin 5 (AQP5) in the apical membrane. The molecular identity of the $\mathrm{K}^{+}$ channel described is unknown (Figure modified from Hollenhorst et al., 2011). 


\section{TRANSEPITHELIAL ROUTES FOR WATER TRANSPORT FROM THE AIRSPACE TO THE INTERSTITIUM}

The mechanisms of water transport across alveolar epithelial cells are poorly understood. Some of the possible water transport routes and mechanisms were discussed in Section "Physiological Origin." Here we further discuss two of these mechanisms.

(1) Water is absorbed from the airspace by a transcellular route via aquaporins. Identification of aquaporins in alveolar epithelial cells suggested that this might be a mechanism for alveolar water transport. Indeed, high levels of aquaporin 5 have been identified in the apical membrane of alveolar epithelial cells (Johnson et al., 2006; Verkman, 2007; Figure 5). However, to date, no water channel has been identified on basolateral membranes of alveolar epithelium. Moreover, the results from studies using aquaporin-deficient mice do not clarify the role of these channels in fluid homeostasis; aquaporin-deficient mice did not exhibit the expected severe phenotypes with regard to distal lung fluid homeostasis (Verkman, 2007).

(2) Water can be absorbed through paracellular, "transjunctional" pathways driven by local osmotic and electrical gradients (Fischbarg, 2010). A major argument in favor of this view is the fact that only small effects on water transport were detected in aquaporin-deficient animals

\section{REFERENCES}

Alpert, P. (2006). Constraints of tolerance: why are desiccation-tolerant organisms so small or rare? J. Exp. Biol. 209, 1575-1584.

Althaus, M., Clauss, W. G., and Fronius, M. (2011). Amiloride-sensitive sodium channels and pulmonary edema. Pulm. Med. 2011, 830320.

Aukland, K. (1984). Distribution of body fluids: local mechanisms guarding interstitial fluid volume. J. Physiol. Paris 79, 395-400.

Aukland, K., and Reed, R. K. (1993). Interstitial-lymphatic mechanisms in the control of extracellular fluid volume. Physiol. Rev. 73, 1-78.

Bachofen, H., and Schurch, S. (2001). Alveolar surface forces and lung architecture. Comp. Biochem. Physiol. Part A Mol. Integr. Physiol. 129, 183-193.

Bardou, O., Trinh, N. T., and Brochiero, E. (2009). Molecular diversity and function of $\mathrm{K}$ channels in airway and alveolar epithelial cells. Am. J. Physiol. Lung Cell Mol. Physiol. 296, L145-L155.

Bastacky, J., Lee, C. Y., Goerke, J., Koushafar, H., Yager, D., Kenaga, L., Speed, T. P., Chen, Y., and Clements, J. A. (1995). Alveolar lining layer is thin and continuous: low-temperature scanning electron microscopy of rat lung. J. Appl. Physiol. 79, 1615-1628.

Billi, D., and Potts, M. (2002). Life and death of dried prokaryotes. Res. Microbiol. 153, 7-12.
Bogdan, R., Veith, C., Clauss, W., and Fronius, M. (2008). Impact of mechanical stress on ion transport in native lung epithelium (Xenopus laevis): short-term activation of $\mathrm{Na}(+)$, $\mathrm{Cl}(-)$ and $\mathrm{K}(+)$ channels. Pflugers Arch. 456, 1109-1120.

Clunes, M. T., and Boucher, R. C. (2007). Cystic Fibrosis: the mechanisms of pathogenesis of an inherited lung disorder. Drug Discov. Today Dis. Mech. 4, 63-72.

Connor, L. M., Bidani, A., Goerke, J., Clements, J. A., and Postlethwait, E. M. (2001). NO2 interfacial transfer is reduced by phospholipid monolayers. J. Appl. Physiol. 91, 2024-2034.

Daniels, C. B., and Orgeig, S. (2003). Pulmonary surfactant: the key to the evolution of air breathing. News Physiol. Sci. 18, 151-157.

Daniels, C. B., Orgeig, S., Sullivan, L. C., Ling, N., Bennett, M. B., Schurch, S., Val, A. L., and Brauner, C. J. (2004). The origin and evolution of the surfactant system in fish: insights into the evolution of lungs and swim bladders. Physiol. Biochem. Zool. 77, 732-749.

Daniels, C. B., Orgeig, S., Wilsen, J., and Nicholas, T. E. (1994). Pulmonary-type surfactants in the lungs of terrestrial and aquatic amphibians. Respir. Physiol. 95, 249-258.

Davis, I. C., and Matalon, S. (2007). Epithelial sodium channels in the adult lung-important modulators of

(Verkman, 2007). This means that the water transport capacity of epithelial tissues in these animals was not significantly affected, whereas their cell membrane permeability for water was drastically decreased (Fischbarg, 2010).

\section{SUMMARY AND CONCLUSION}

We conclude that: (1) the alveolar fluid is highly conserved within all air-breathing vertebrate classes and that it is a characteristic and crucial element of the blood-gas barrier; (2) the alveolar fluid originates from the inside of the body and it is necessary for several physiological functions enabling effective gas exchange. (3) Conditions accompanied by impaired alveolar fluid content and composition are associated with severe diseases. (4) There are ion and water transport mechanisms that regulate and maintain the water content of the alveolar fluid. However, these mechanisms are far from being understood. Clearly, the alveolar fluid is an anatomically and physiologically essential part of the alveolar-capillary barrier. We suggest that the air-blood barrier in air-breathing vertebrates is formed by four plies instead of three, as suggested in recent models.

\section{ACKNOWLEDGMENTS}

The authors would like to thank Monika I. Hollenhorst, Johannes Strauss, and Blake Haller for comments and critical discussions during editing of the manuscript.

pulmonary health and disease. $A d v$. Exp. Med. Biol. 618, 127-140.

Dierichs, R. (1973). Electron microscopic studies on the lung of the frog. I. Demonstration of the alveolar lining layer (surfactant). Z. Zellforsch. Mikrosk. Anat. 137, 553-561.

Dobbs, L. G., and Johnson, M. D. (2007). Alveolar epithelial transport in the adult lung. Respir. Physiol. Neurobiol. 159, 283-300.

Fang, X., Song, Y., Hirsch, J., Galietta, L. J., Pedemonte, N., Zemans, R. L., Dolganov, G., Verkman, A. S., and Matthay, M. A. (2006). Contribution of CFTR to apical-basolateral fluid transport in cultured human alveolar epithelial type II cells. Am. J. Physiol. Lung Cell Mol. Physiol. 290, L242-L249.

Fick, A. (1855). Ueber diffusion. Ann. Phys. 170, 59-86.

Fischbarg, J. (2010). Fluid transport across leaky epithelia: central role of the tight junction and supporting role of aquaporins. Physiol. Rev. 90, 1271-1290.

Fischer, H., Van Driessche, W., and Clauss, W. (1989). Evidence for apical sodium channels in frog lung epithelial cells. Am. J. Physiol. 256, C764-C771.

Ganz, T. (2003). Defensins: antimicrobial peptides of innate immunity. Nat. Rev. Immunol. 3, 710-720.

Garty, H., and Palmer, L. G. (1997) Epithelial sodium channels: function, structure, and regulation. Physiol. Rev. 77, 359-396.
Goerke, J. (1998). Pulmonary surfactant: functions and molecular composition. Biochim. Biophys. Acta 1408, 79-89.

Greenwood, I. A., Yeung, S. Y., Hettiarachi, S., Andersson, M., and Baines, D. L. (2009). KCNQencoded channels regulate $\mathrm{Na}+$ transport across H441 lung epithelial cells. Pflugers Arch. 457, 785-794.

Hamann, S., Herrera-Perez, J. J., Zeuthen, T., and Alvarez-Leefmans, F. J. (2010). Cotransport of water by the $\mathrm{Na}+-\mathrm{K}+-2 \mathrm{Cl}(-)$ cotransporter NKCC1 in mammalian epithelial cells. J. Physiol. (Lond.) 588, 4089-4101.

Hollenhorst, M. I., Richter, K., and Fronius, M. (2011). Ion transport by pulmonary epithelia. J. Biomed. Biotechnol. 2011, 174306.

Hoschele, S., and Mairbaurl, H. (2003). Alveolar flooding at high altitude: failure of reabsorption? News Physiol. Sci. 18, 55-59.

Jeffery, P. K., and Reid, L. (1975). New observations of rat airway epithelium: a quantitative and electron microscopic study. J. Anat. 120, 295-320.

Johnson, M. D., Bao, H. F., Helms, M. N., Chen, X. J., Tigue, Z., Jain, L., Dobbs, L. G., and Eaton, D. C. (2006). Functional ion channels in pulmonary alveolar type I cells support a role for type I cells in lung ion transport. Proc. Natl. Acad. Sci. U.S.A. 103, 4964-4969. 
Kimura, T., Kawabe, H., Jiang, C., Zhang, W., Xiang, Y. Y., Lu, C., Salter, M. W., Brose, N., Lu, W. Y., and Rotin, D. (2011). Deletion of the ubiquitin ligase Nedd4L in lung epithelia causes cystic fibrosis-like disease. Proc. Natl. Acad. Sci. U.S.A. 108, 3216-3221.

Kleiner, S. M. (1999). Water: an essential but overlooked nutrient. J. Am. Diet. Assoc. 99, 200-206.

Koefoed-Johnsen, V., and Ussing, H. H. (1958). The nature of the frog skin potential. Acta Physiol. Scand. 42, 298-308.

Krumm, S., Goebel-Lauth, S. G., Fronius, M., and Clauss, W. (2005). Transport of sodium and chloride across earthworm skin in vitro. $J$. Comp. Physiol. B 175, 601-608.

Kylstra, J. A. (1974). Liquid breathing. Undersea Biomed. Res. 1, 259-269.

Ladanyi, E., Ahuja, R. C., Mobius, D., and Stalder, K. (1992). Oxygen transport through a model lung surfactant surface layer: influence of the film compression on the kinetics. Adv. Exp. Med. Biol. 317, 343-347.

Lambrecht, B. N. (2006). Alveolar macrophage in the driver's seat. Immunity 24, 366-368.

Levis, B. M., Lin, T. H., Noe, F. E., and Hayford-Welsing, E. J. (1959). The measurement of pulmonary diffusing capacity for carbon monoxide by a rebreathing method. J. Clin. Invest. 38, 2073-2086.

Lindert, J., Perlman, C. E., Parthasarathi, K., and Bhattacharya, J. (2007). Chloride-dependent secretion of alveolar wall liquid determined by optical-sectioning microscopy. Am. J. Respir. Cell Mol. Biol. 36, 688-696.

Maggiorini, M. (2006). High altitudeinduced pulmonary oedema. Cardiovasc. Res. 72, 41-50.

Maina, J. N. (2000). Comparative respiratory morphology: themes and principles in the design and construction of the gas exchangers. Anat. Rec. 261, 25-44.

Maina, J. N. (2002). Functional Morphology of the Vertebrate Respiratory System. Biological Systems in Vertebrates, Vol. 1 (Enfield: Science Publisher Inc).

Maina, J. N., and West, J. B. (2005). Thin and strong! The bioengineering dilemma in the structural and functional design of the blood-gas barrier. Physiol. Rev. 85, 811-844.

Mairbaurl, H., Wodopia, R., Eckes, S., Schulz, S., and Bartsch, P. (1997). Impairment of cation transport in A549 cells and rat alveolar epithelial cells by hypoxia. Am. J. Physiol. 273, L797-L806.

Mall, M., Gonska, T., Thomas, J., Schreiber, R., Seydewitz, H.
H., Kuehr, J., Brandis, M., and Kunzelmann, K. (2003). Modulation of Ca2+-activated Cl- secretion by basolateral $\mathrm{K}+$ channels in human normal and cystic fibrosis airway epithelia. Pediatr. Res. 53, 608-618.

Mall, M., Grubb, B. R., Harkema, J. R., O'Neal, W. K., and Boucher, R. C. (2004). Increased airway epithelial $\mathrm{Na}+$ absorption produces cystic fibrosis-like lung disease in mice. Nat. Med. 10, 487-493.

Mall, M., Wissner, A., Schreiber, R., Kuehr, J., Seydewitz, H. H., Brandis, M., Greger, R., and Kunzelmann, K. (2000). Role of K(V)LQT1 in cyclic adenosine monophosphatemediated $\mathrm{Cl}(-)$ secretion in human airway epithelia. Am. J. Respir. Cell Mol. Biol. 23, 283-289.

Martin, T. R. (2000). Recognition of bacterial endotoxin in the lungs. Am. J. Respir. Cell Mol. Biol. 23, 128-132.

Matthay, M. A., Folkesson, H. G., and Clerici, C. (2002). Lung epithelial fluid transport and the resolution of pulmonary edema. Physiol. Rev. 82, 569-600.

Meban, C. (1973). The pneumonocytes in the lung of Xenopus laevis. J. Anat. 114, 235-244.

Murray, J. F. (2011). Pulmonary edema: pathophysiology and diagnosis. Int. J. Tuberc. Lung Dis. 15, 155-160.

Ng, A. W., Bidani, A., and Heming, T. A. (2004). Innate host defense of the lung: effects of lung-lining fluid $\mathrm{pH}$. Lung 182, 297-317.

Okada, Y., Ishiko, S., Daido, S., Kim, J., and Ikeda, S. (1962). Comparative morphology of the lung with special reference to the alveolar epithelial cells. I. Lung of the amphibia. Acta Tuberc. Jpn. 11, 63-72.

Orgeig, S., Bernhard, W., Biswas, S. C., Daniels, C. B., Hall, S. B., Hetz, S. K., Lang, C. J., Maina, J. N., Panda, A. K., Perez-Gil, J., Possmayer, F., Veldhuizen, R. A., and Yan, W. (2007). The anatomy, physics, and physiology of gas exchange surfaces: is there a universal function for pulmonary surfactant in animal respiratory structures? Integr. Comp. Biol. 47, 610-627.

Pack, R. J., Al-Ugaily, L. H., and Morris, G. (1981). The cells of the tracheobronchial epithelium of the mouse: a quantitative light and electron microscope study. J. Anat. 132, 71-84.

Planes, C., Blot-Chabaud, M., Matthay, M. A., Couette, S., Uchida, T., and Clerici, C. (2002). Hypoxia and beta 2-agonists regulate cell surface expression of the epithelial sodium channel in native alveolar epithelial cells. J. Biol. Chem. 277, 47318-47324.
Planes, C., Friedlander, G., Loiseau, A. Amiel, C., and Clerici, C. (1996). Inhibition of $\mathrm{Na}$-K-ATPase activity after prolonged hypoxia in an alveolar epithelial cell line. Am. J. Physiol. 271, L70-L78.

Rantamaki, A. H., Telenius, J., Koivuniemi, A., Vattulainen, I., and Holopainen, J. M. (2011). Lessons from the biophysics of interfaces: lung surfactant and tear fluid. Prog. Retin. Eye Res. 30, 204-215.

Riordan, J. R., Rommens, J. M., Kerem, B., Alon, N., Rozmahel, R., Grzelczak, Z., Zielenski, J., Lok, S., Plavsic, N., Chou, J. L., Drumm, M. L., Lannuzz, M. C., Collina, F. S., and Tusi, L. P. (1989). Identification of the cystic fibrosis gene: cloning and characterization of complementary DNA. Science 245, 1066-1073.

Scarpelli, E. M. (2003). Physiology of the alveolar surface network. Comp. Biochem. Physiol. Part A Mol. Integr. Physiol. 135, 39-104.

Sommer, D., Bogdan, R., Berger, J., Peters, D. M., Morty, R. E., Clauss, W. G., and Fronius, M. (2007). CFTR-dependent Cl- secretion in Xenopus laevis lung epithelium. Respir. Physiol. Neurobiol. 158, 97-106.

Staub, N. C. (1970). The pathophysiology of pulmonary edema. Hum. Pathol. 1, 419-432.

Stoltz, D. A., Meyerholz, D. K., Pezzulo, A. A., Ramachandran, S., Rogan, M. P., Davis, G. J., Hanfland, R. A., Wohlford-Lenane, C., Dohrn, C. L., Bartlett, J. A., Nelson, G. A. T., Chang, E. H., Taft, P. J., Ludwig, P. S., Estin, M., Hornick, E. E., Launspach, J. L., Samuel, M., Rokhlina, T. Karp, P. H., Ostedgaard, L. S., Uc, A., Starner, T. D., Horswill, A. R., Brogden, K. A., Prather, R. S., Richter, S. S., Shilyansky, J., McCray, P. B. J., Zabner, J., and Welsh, M. J. (2010). Cystic fibrosis pigs develop lung disease and exhibit defective bacteria eradication at birth. Sci. Transl. Med. 2, 29-31.

Stone, K. C., Mercer, R. R., Gehr P., Stockstill, B., and Crapo, J. D. (1992). Allometric relationships of cell numbers and size in the mammalian lung. Am. J. Respir. Cell Mol. Biol. 6, 235-243.

Sznajder, J. I. (2001). Alveolar edema must be cleared for the acute respiratory distress syndrome patient to survive. Am. J. Respir. Crit. Care Med. 163, 1293-1294.

Tarran, R., Button, B., and Boucher, R. C. (2006). Regulation of normal and cystic fibrosis airway surface liquid volume by phasic shear stress. Annu. Rev. Physiol. 68, 543-561.
Verkman, A. S. (2007). Role of aquaporins in lung liquid physiology. Respir. Physiol. Neurobiol. 159, 324-330.

Weber, W. M., Dannenmaier, B., and Clauss, W. (1993). Ion transport across leech integument. I. Electrogenic $\mathrm{Na}+$ transport and current fluctuation analysis of the apical $\mathrm{Na}+$ channel. J. Comp. Physiol. B 163, 153-159.

Weibel, E. R. (2009). What makes a good lung? Swiss. Med. Wkly. 139, 375-386.

Weibel, E. R., Federspiel, W. J., FryderDoffey, F., Hsia, C. C., Konig, M., Stalder-Navarro, V., and Vock, R. (1993). Morphometric model for pulmonary diffusing capacity. I. Membrane diffusing capacity. Respir. Physiol. 93, 125-149.

Wilson, S. M., Brown, S. G., McTavish, N., McNeill, R. P., Husband, E. M., Inglis, S. K., Olver, R. E., and Clunes, M. T. (2006). Expression of intermediate-conductance, $\mathrm{Ca} 2+$ activated $\mathrm{K}+(\mathrm{KCNN} 4)$ in $\mathrm{H} 441$ human distal airway epithelial cells. Am. J. Physiol. Lung Cell Mol. Physiol. 291, L957-L965.

Wodopia, R., Ko, H. S., Billian, J. Wiesner, R., Bartsch, P., and Mairbaurl, H. (2000). Hypoxia decreases proteins involved in epithelial electrolyte transport in A549 cells and rat lung. Am. J. Physiol. Lung Cell Mol. Physiol. 279, L1110-L1119.

Zeuthen, T. (2010). Water-transporting proteins. J. Membr. Biol. 234, 57-73.

Conflict of Interest Statement: The authors declare that the research was conducted in the absence of any commercial or financial relationships that could be construed as a potential conflict of interest.

Received: 16 November 2011; paper pending published: 14 December 2011; accepted: 01 May 2012; published online: 22 May 2012.

Citation: Fronius $M$, Clauss WG and Althaus $M$ (2012) Why do we have to move fluid to be able to breathe? Front. Physio. 3:146. doi: 10.3389/fphys.2012.00146

This article was submitted to Frontiers in Membrane Physiology and Biophysics, a specialty of Frontiers in Physiology.

Copyright (c) 2012 Fronius, Clauss and Althaus. This is an open-access article distributed under the terms of the Creative Commons Attribution Non Commercial License, which permits non-commercial use, distribution, and reproduction in other forums, provided the original authors and source are credited. 